И.С.Гущин

\title{
Устранение неизбежности аллергического ответа
}

\author{
ФГБУ "ГНЦ Институт иммунологии ФМБА России": 115478, Москва, Каширское ш., 24, к. 2
}

\section{I.S.Gushchin \\ Prevention of allergic imminence}

Key words: allergen-specific immune therapy, allergic disease, thymic stromal lymphopoietin (TSLP), immunoglobulin E, cytokines, Th2 cells, receptors.

Ключевые слова: аллерген-специфическая иммунотерапия, аллергические заболевания, тимический стромальный лимфопоэтин TSLP, иммуноглобулин Е, цитокины, Th2-клетки, рецепторы.

Рост частоты аллергических заболеваний за последние 30-40 лет превысил все ожидаемые показатели. Действительно, в настоящее время 25-40 \% населения разных стран страдают IgE-опосредованными аллергическими заболеваниями ( $\mathrm{IgE}$ - иммуноглобулин Е), такими как бронхиальная астма (БА), аллергический риноконъюнктивит, атопический дерматит, и их распространенность продолжает повышаться, особенно среди детей $[1,2]$. Появившиеся сообщения о том, что за последние годы этот рост приостановился [3, 4], к сожалению, не подтвердились. Недавно выполненный систематизированный обзор всемирных эпидемиологических данных продемонстрировал на примере БА, что в настоящее время признаки снижения частоты и распространенности аллергических заболеваний отсутствуют [5]. Создается впечатление, что скоро аллергия станет обязательным спутником большинства людей. Таким образом, исследования, направленные на выяснение сущности аллергии, становятся все более актуальными.

Общая схема аллергической реакции I типа (IgEопосредованной), приведенная в 1964 г. в наиболее популярной классификации реакций гиперчувствительности [6], остается вполне приемлемой и сегодня. Однако имеющиеся фактические данные, особенно собранные в последние 10 лет, позволяют расширить эти представления. Принципиальное же понимание сущности аллергической реактивности за этот период почти не изменилось. До сих пор аллергию часто рассматривают как результат "ненормального" ответа организма на экзогенные, и как считают, "безобидные" молекулы [7]. Такая оценка сохранялась на всех этапах приобретения новых сведений, относящихся к механизму аллергии. В 70-е годы XX в. аллергия нередко приравнивалась к состоянию, характеризующемуся повышением в крови антител, преимущественно изотипа IgE. Затем стали считать, что у некоторых лиц иммунная система имеет предрасположенность к формированию Th2-ответа (Th2 - T-хелперные клетки II типа). В настоящее время аллергия рассматривается как нарушение регуляторных звеньев ответной иммунологической реакции, облегченное особенной гене- тической конституцией или вызванное некоторыми воздействиями среды. Особое место в этих представлениях отводится средовым эпигенетическим механизмам пре- и постнатального формирования предрасположенности к аллергии у потомства [8-10].

\section{Трансбарьерное проведение аллергена - механизм принуждения к аллергическому ответу}

На протяжении последних 20 лет появилось множество сведений, подтверждающих, что аллергия является, скорее, обязательным (вынужденным), чем случайным ответом организма на проникновение в него аллергенов / антигенов преимущественно через барьерные ткани в определенном дозовом и временном режиме [11-13]. В этом случае она рассматривается как следствие поражения гисто-гематических барьеров (опосредованного как генетическими, так и средовыми факторами), которое состоит в организации аллерген-специфического воспаления и проявляется реакцией гиперчувствительности. Биологическая основа этого процесса, как и любой реакции воспаления, заключается в отграничении зоны действия повреждающего агента (в данном случае - аллергена) и в удалении его из организма.

Это представление подкрепляется постоянно пополняемым обширным экспериментальным и клиническим материалом, позволяющим определенно считать, что, во-первых, повышение проницаемости барьерных тканей для аллергена облегчает формирование аллергии, а, во-вторых, у больных аллергией выявляются признаки этой повышенной проницаемости. Это справедливо по отношению к разным естественным барьерным тканям, но наиболее показательным в данном случае является эпидермальный барьер. На этом примере установлены конкретные клинически значимые формы повышения барьерной проницаемости, обусловленные действием как средовых, так и генетических факторов. Наиболее убедительной иллюстрацией последних являются данные о том, что у больных с аллергией (в частности, с атопическим дерматитом) генетически обусловленная повышенная проницаемость кожи связана с множественными локусами на хромосоме, 
в которой располагается эпидермальный дифференцировочный локус ( 30 генов, кодирующих белки построения и регуляции функции эпидермального барьера). При этом сильным предрасполагающим генетическим фактором является утрата функции гена филагрина - ключевого белка, участвующего в конечной дифференцировке эпидермиса и образовании кожного барьера. Причем обнаруженные у человека варианты мутаций этого гена различаются по клиническому фенотипу.

Сведения о том, что прохождение аллергенов в определенном дозово-временном режиме через естественные барьеры является важнейшим фактором индукции аллергической формы реагирования, позволяют сделать предположение о существовании функционального звена, опосредующего направление ответной реакции в сторону предпочтительного образования аллергических антител (антител изотипа $\mathrm{IgE}$ ) и подготовку клеточных участников аллергической реакции. В последнее время получены данные о том, что наиболее вероятным кандидатом (возможно, далеко не единственным) может быть молекула тимического стромального лимфопоэтина (TSLP - thymic stromal lymphopoietin). Природа и свойства TSLP подробно описаны в нескольких исчерпывающих литературных обзорах [14-17]. Здесь же стоит обсудить лишь основные данные, относящиеся к обсуждаемому вопросу.

TSLP является отдаленным родственником интерлейкина-7 (IL-7), принадлежащего к большому цитокиновому семейству интерлейкина-2 (IL-2, IL-4, Il-7, IL-9, IL-13, IL-15, IL-21 и TSLP). Впервые TSLP идентифицирован в надосадочной жидкости клеток стромы тимуса мышей как фактор, обеспечивающий пролиферацию В-клеток. Активность TSLP мыши перекрывает таковую IL-7, который является гемопоэтическим фактором роста, секретируемым клетками стромы костного мозга и тимуса, и стимулирует дифференцировку плюрипотентных гемопоэтических стволовых клеток в лимфоидные клеткипредшественники и пролиферацию лимфоидных клеток (B-, T- и NK-клеток). TSLP и другие цитокины этой группы представляют собою мономерный относительно небольшой белок (140 аминокислотных остатков) в виде пучка 4 спирализованных доменов с 3 участками N-гликозилирования и 7 остатками цистеина. TSLP человека, хотя и имеет относительно невысокую гомологию с TSLP мыши по аминокислотной последовательности (порядка $43 \%$ аминокислотных остатков), но обладает принципиально сходной спирализованной структурой с 2 участками $\mathrm{N}$-гликозилирования и 6 остатками цистеина. Следует отметить, что TSLP как человека, так и мышей преимущественно экспрессируется эпителиальными клетками, в особенности в легких, коже, кишечнике, и его функциональные свойства оказываются сходными.

TSLP осуществляет свое действие на клетки через рецептор (TSLPR), который является атипичным: вместо $\gamma$-цепи, общей для всех других рецепторов интерлейкинов этой группы, он имеет специфичную для TSLPR субъединицу, родственную $\gamma$-цепи (идентичность по $24 \%$ аминокислотных остатков). Другая субъединица идентична $\alpha$-цепи рецептора для IL-7 (IL-7R $\alpha$ ). TSLP связывается с TSLPR с низкой аффинностью, но взаимодействие с IL-7R $\alpha$ значительно повышает аффинность связывания. Транскрипт TSLPR определяется в дендритных клетках, периферических $\mathrm{CD}^{+}{ }^{+}$-клетках, тучных клетках и миелоидных клетках человека и мыши. Эти данные позволяют предположить, что у TSLP имеется довольно широкий функциональный диапазон. Вместе с тем у человека миелоидные дендритные клетки экспрессируют TSLPR в наибольшей степени по сравнению с другими клетками - как по уровню транскрипта, так и самого белка. Это обстоятельство позволяет допустить, что они являются первичными отвечающими клетками на этот цитокин эпителиального происхождения.

Тот факт, что TSLP человека может очень сильно активировать CD11 ${ }^{+}$незрелые дендритные клетки (в культуральных условиях), свидетельствует о ранее неизвестной биологической функции TSLP, прямо указывающей на связь цитокина эпителиального происхождения с опосредуемым дендритными клетками развитием аллергического ответа.

Дендритные клетки, как известно, являются антигенпредставляющими: воспринимают проникший в организм антиген и затем представляют его переработанные фрагменты Т-клеткам. Человеческие дендритные клетки, экспрессирующие TSLPR в высокой степени, отвечают на действие TSLP быстрым повышением количества на клеточной поверхности таких молекул, как MHC II класса, CD40, CD80, CD86 и маркера активации дендритных клеток - DC-lamp (dendritic cell-lysosomal associated membrane protein). В отличие от других стимуляторов дендритных клеток (лигандов toll-подобных рецепторов и CD40L), TSLP не вызывает продукции цитокинов, характерных для поляризации в сторону Th1-ответа (IL-12, провоспалительных цитокинов фактора некроза опухоли- $\alpha$ (TNF- $\alpha$ ), IL-1 $\beta$ и IL-6), не индуцирует в миелоидных дендритных клетках экспрессию mРНК, кодирующих семейство интерлейкина-12 (IL-12, IL-23, IL-27) или интерферонов (INF) I типа, которые, как известно, вызывают дифференцировку Th1-клеток.

В миелоидных дендритных клетках TSLP вызывает образование ряда цитокинов, включающих в себя положительный хемотаксис Th2-клеток (T-helper type attracting chemokine - TARC), I-309/CCL1 (также обладающих хемотаксическим действием по отношению к Th2-клеткам), эотаксина-2, IL-8, которые важны для вовлечения в ответ Th2-клеток и других участников аллергического ответа (эозинофилов, нейтрофилов). Эти данные позволили предположить, что наиболее заметная функция TSLP заключается в его способности наделять дендритные клетки свойством индуцировать Тh2-тип ответа и одновременно снижать продукцию цитокинов, осуществляющих поляризацию в сторону Th1-ответа.

Накопилось немало данных, полученных как в эксперименте на животных, так и в наблюдениях 
людей в условиях in vivo, которые свидетельствуют о высокой экспрессии TSLP в эпителиальных клетках слизистых оболочек и кератиноцитах при аллергическом воспалении. Это лишний раз подтверждает высокую вероятность участия TSLP в передаче информации от эпителиального покрова дендритным клеткам, находящимся в тесном контакте с ним. Последствием такой информации является организация микроокружения, допускающего (разрешающего) переключение иммунного ответа на Th2-тип.

Как полагают, этот разрешающий сигнал состоит в том, что активированные цитокином TSLP дендритные клетки индуцируют воспалительные Th2клетки и поддерживают пул Тh2-клеток памяти. На миелоидных дендритных клетках человека, активированных TSLP, быстро возрастает представленность TSLPR в значительно большей степени, чем на преактивированных CD4+ T-лимфоцитах.

Зрелые дендритные клетки, индуцированные TSLP, опосредуют дифференцировку наивных CD4 ${ }^{+}$ Т-клеток в особый тип Тh2-клеток. Особенность их состоит в том, что они образуют наряду с типичными для Th2-клеток цитокинами (IL-4, IL-13, IL-5) относительно большое количество провоспалительного цитокина - TNF- $\alpha$, но очень мало IL-10. Помимо этого, активированные дендритные клетки могут запускать дифференцировку $\mathrm{CD}^{+} \mathrm{T}$-клеток в так называемые "проаллергические цитотоксические Т-клетки", которые продуцируют IL-13.

В экспериментах на мышах получены сходные данные о способности TSLP вызывать созревание и активацию дендритных клеток, которые, в свою очередь, индуцируют дифференцировку наивных CD4+ ${ }^{+}$-кллеток в Th2-клетки. Таким образом, описанное свойство TSLP является универсальным, проявляющимся у разных видов животных.

Помимо прочего, дендритные клетки, активированные TSLP, вызывают значительный прирост и Th2-клеток памяти, проходящих последующую Th2-поляризацию и экспрессирующих гены проаллергических белков - рецептора для IL-25 (IL-25R, иначе обозначаемого как IL-17RB), белка кристаллов Шарко-Лейдена, синтазы простагландина D2.

Ключевым механизмом проаллергического влияния активированных TSLP дендритных клеток является взаимодействие 2 молекул - OX40L (CD252) на поверхности дендритной клетки и OX40 (CD134) на поверхности активированной $\mathrm{CD}^{+} \mathrm{T}$-клетки. Лиганд OX40L (гликопротеин с молекулярной массой 34 кДа) экспрессируется дендритными клетками, активированными TSLP, и вступает в связь со своим рецептором - OX40, представленным на мембране активированных $\mathrm{CD}^{+}{ }^{+}$Т-клеток. В отличие от других костимулирующих молекул (CD28), участвующих в премировании Т-клеток, ОХ40 конститутивно не экспрессирован на наивных Т-клетках и индуцируется через 24-48 ч после связывания антигена с Т-клеточным рецептором (TCR). Это очень важное обстоятельство, т. к. оно показывает, что последующее отклонение в сторону Th2-ответа, провоцируемое взаимодействием OX40L и OX40, возмож- но лишь после антигенной подготовки Т-клеток, т. е. это склонение сохраняет высокую антигенную специфичность.

Основная функция TSLP, склоняющая вызванную аллергеном реакцию в сторону Th2-ответа, проиллюстрировна на рис. 1 [18].

Блокада взаимодействия OX40L c OX40, осуществляемая нейтрализующими антителами к OX40L, тормозит продукцию Th2-цитокинов и TNF- $\alpha$, но усиливает образование IL-10 дифференцированными CD4+ T-клетками, сокультивируемыми с активированными дендритными клетками. Дифференцировка воспалительных Th2-клеток, индуцированных OX40L, происходит в отсутствие IL-12 (IL-12 блокирует этот процесс).

Наконец, in vivo показано, что моноклональные антитела против OX40L угнетают продукцию Th2цитокинов и аллергенспецифического IgE. Кроме того, эпидермальная индукция образования TSLP усиливает системный иммунный ответ на сенсибилизирующий аллерген, о чем свидетельствует прирост концентрации в крови животных (мышей) аллерген-специфического IgE [19].

Таким образом, оказывается вполне вероятным, что трансэпителиальное прохождение аллергена является стимулом к продукции эпителиальными клетками TSLP. Будучи активированными TSLP, дендритные клетки за счет экспрессии OX40L создают условия, разрешающие Th2-ответ, но не допускающие продукцию Th1-поляризующих цитокинов. Тем самым осуществляется направление ответа на синтез антител изотипа IgE и параллельно подготавливается более активное вовлечение в процесс Th2-клеток при

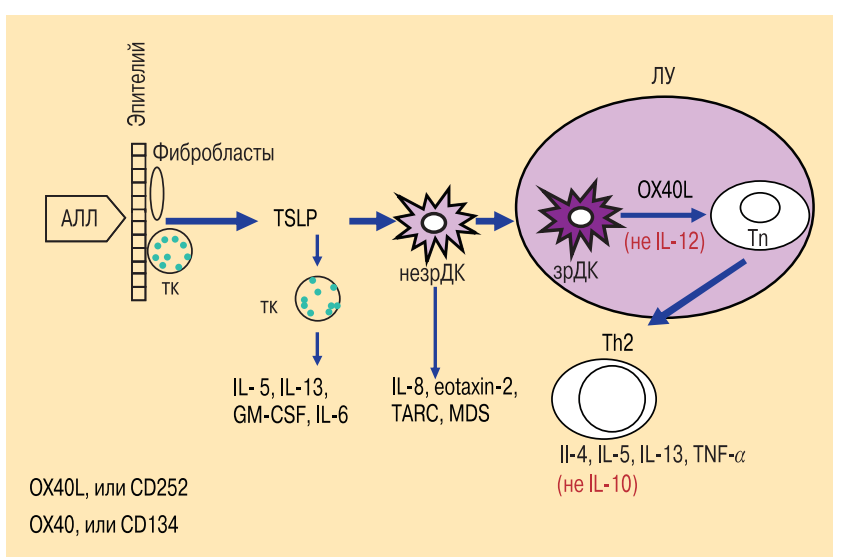

Рис. 1. Трансбарьерное склонение в сторону Th2-ответа [16] Примечание: Трансэпителиальное действие аллергена (на эпителиальные клетки слизистых тканей, кератиноциты, а также фибробласты, тучные клетки кожи) вызывает образование TSLP, который активирует незрелые (незр) дендритные клетки (ДК), что сопровождается образованием IL-8 и эотаксина-2, а также хемокинов, привлекающих Th2-клетки (TARC, хемокина макрофагального происхождения - MDC), осушествляет костимуляцию тучных клеток, продуцирующих IL-5, IL-13, а также GM-CSF и IL-6. ДК, активированные TSLP, созревают и мигрируют в регионарные лимфоузлы (ЛУ), чтобы обеспечить аллергический иммунный ответ. При этом ДК (активированные) экспрессируют OX40L, который запускает дифференцировку аллерген-специфических наивных $\mathrm{CD}^{+}{ }^{-} \mathrm{T}$-клеток (Tn) в воспалительные Th2-клетки, продуцирующие IL-4, IL-5, IL-13 и TNF- $\alpha$, но не IL-10. Воспалительные Th2-клетки мигрируют затем в места развития аллергического воспалительного ответа, привлекаемые цитокинами TARC и MDC. Цитокины, производимые воспалительными Th2-клетками (IL-4, IL-5, IL-13, TNF- $\alpha$ ), приступают к формированию аллергического ответа за счет запуска образования IgE-антител, продукции слизи, эозинофилии. 
повторных проникновениях аллергена через тканевые барьеры.

Клинические и экспериментальные данные свидетельствуют о том, что вне периода аллергенных провокаций в легочной ткани сенсибилизированного организма сохраняются клетки, соответствующие Th2-клеткам памяти. Эти клетки превращаются в активированные эффекторы при экспозиции аллергена. Поддержание и активация Th2-клеток памяти также осуществляется при участии дендритных клеток, активированных TSLP. Последние вызывают повышенную экспрессию активированными Тh2клетками памяти рецептора IL-17RB (IL-25R), с которым взаимодействует IL-17E (до недавнего времени обозначавшийся как IL-25). Одним из свойств IL-17E (IL-25) является стимуляция продукции Th2цитокинов. Источником образования IL-17E в зоне аллергической реакции могут выступать различные клетки, участвующие в аллергическом ответе (эпителиальные клетки, а также тучные клетки, базофилы, эозинофилы). В этом можно усмотреть высокую степень надежности включения в процесс Th2-клеток в зоне аллергической реакции, когда на них представлен IL-17RB.

Таким образом, можно говорить об определенной регуляторной положительной обратной связи между эффекторным звеном аллергического процесса и собственно иммунологическим звеном, что, в конечном счете, ведет к закреплению и усилению аллергического воспаления.

Приведенный фактический материал позволяет сделать важное заключение: поступление аллергена через барьерные ткани, с одной стороны, создает разрешающий сигнал для запуска Th2-ответа (IgEответа), а с другой - переводит готовность к последующим встречам организма с аллергеном на новый облегченный уровень воспроизведения аллергического воспаления. Итак, существенным достижением последнего времени можно считать обнаружение конкретной молекулы, инициирующей эти функции, - TSLP. Вполне вероятно, что это важный, но далеко не единственный передатчик сигнала о необходимости включения аллергического ответа на проникновение аллергена в организм.

$\mathrm{IgE}-\mathrm{Fc} \varepsilon \mathrm{RI}$ - уникальный механизм рецепции аллергена и клеточной активации. По мере накопления новых сведений становится все более очевидной завершенная организация аллергического процесса, тонкая "приспособленность" каждого из его звеньев друг к другу.

Прежде всего, это относится к функции молекулы IgE, имеющей уникальное строение, обеспечивающее строго "нормированное" ее взаимодействие со своим высокоаффинным рецептором, представленным на основных клетках-мишенях аллергического процесса [20-22]. Как было хорошо известно, молекула $\operatorname{IgE~отличается~от~IgG~тем~у~нее~не~3,~а~} 4$ константных домена в тяжелых цепях и нет шарнирной области, что делает ее менее гибкой. Позднее было сделано важное открытие, установившее особенность пространственной структуры IgE. Оказалось, что молекула IgE имеет жесткую (ригидную) асимметричную форму.

На основании спектроскопических исследований в растворе с измерением расстояния между хромофорами, включенными в концевые участки молекулы, показано методом резонансной передачи энергии, что расстояние между антиген-связывающими участками и С-концами 4-го константного домена (Сє4) иммуноглобулина составляет 6,9 нм. В плоской структуре оно должно было соответствовать 17,5 нм. Поэтому единственным объяснением обнаруженного факта явилось допущение того, что молекула IgE имеет изогнутое строение. Такая изогнутая структура характерна не только для IgE, находящегося в растворе, но и в фиксированной форме на высокоаффинном рецепторе $\left(\mathrm{Fc}_{\varepsilon} \mathrm{RI}\right)$.

Представление о такой компактной асимметричной структуре молекулы IgE находится в соответствии и с более ранними данными рентгеноструктурного анализа, и с более поздними сведениями, полученными методом нейтронного рассеивания.

Из данных об асимметричной изогнутой структуpe IgE следует важный вывод о характере взаимодействия этой молекулы с $\mathrm{Fc}_{\varepsilon} \mathrm{RI}$. Полагают, что изогнутая структура делает более доступными участки в молекуле $\operatorname{IgE~к~взаимодействию~с~соответствую-~}$ щим участком $\mathrm{Fc}_{\varepsilon} \mathrm{RI}$ и облегчает связывание обеих молекул в соотношении $1: 1$, что согласуется с ранее известными экспериментальными данными. Корме того, молекулярное соотношение изолированного $\mathrm{Fc}$-фрагмента IgE при соединении в растворе с изолированным участком связывания рецептора соответствует $1: 1$. Это соответствует представлению о том, что сам по себе Fc-фрагмент находится в изогнутом состоянии. Действительно, последнее было подтверждено результатами изучения рассеивания рентгеновских лучей и нейтронного пучка. Вероятнее всего, изгиб находится между константными доменами С 22 и С 83 , т. е. вблизи от той области, которая отвечает за связывание с рецептором.

Удалось представить довольно четкую картину в 3-мерной структуре $\operatorname{IgE}$ протяженного участка, охватывающего оба Сє3-домена. Положение связывающих участков в ней таково, что в изогнутом Fcє-фрагменте они с одной стороны молекулы (выгнутой, выпуклой) открыты для взаимодействия, a с другой (вогнутой) - скрыты. Это лишний раз доказывает, что асимметричная изогнутая структура $\mathrm{IgE}$ (и его Fc-фрагмента) надежно обеспечивает молекулярное соотношение $1: 1 \mathrm{IgE} \mathrm{K} \mathrm{Fc}_{\varepsilon} \mathrm{RI}$.

Высокая аффинность IgE к Fc $\mathrm{FI}_{\varepsilon}$ (в отличие от аффинности IgG к своим рецепторам) может также объясняться изогнутой ригидной структурой $\mathrm{IgE}$. В противоположность гибкой структуре $\mathrm{IgG}$, жесткая выгнутая форма IgE обеспечивает, во-первых, высокую доступность участка связывания (область Cع3-домена) для взаимодействия с $\mathrm{Fc}_{\varepsilon} \mathrm{RI}$, a, во-вторых, облегчает затем вовлечение в процесс взаимодействия и С 2 -домена.

Полагают, что С 2 -домен выполняет в связывании $\operatorname{IgE~} \mathrm{c} \mathrm{Fc}_{\varepsilon} \mathrm{RI}$ определенную вспомогательную 
функцию, обеспечивающую сдерживание диссоциации комплекса $\mathrm{IgE}-\mathrm{Fc}_{\varepsilon} \mathrm{RI}$. Это достигается тем, что после начального этапа связывания пары Сє3-доменов рецептором происходят конформационные изменения, вовлекающие пару Сє2-доменов, закрепляющихся на 2-й точке связывания с рецептором. Так создается конечное повышение аффинности и замедление диссоциации всего комплекса.

Такому представлению соответствуют данные работ, в которых показано, что кинетика связывания IgE c Fcع RI имеет 2-фазный характер. Это согласуется с представлением о конформационном сдвиге, наступающем после начального этапа связывания Cع 3 со 2-м доменом (D2) $\alpha$-цепи высокоаффинного рецептора Fce RI. B свободном состоянии IgE пара Cह3-доменов находится в конфигурации, при которой одна поверхность доменов открыта для взаимодействия (на выгнутой стороне), а другая - прикрыта Fab-фрагментами ("открыто-закрытая" конфигурация). На начальной стадии фиксации устанавливается связь обоих доменов С 23 с D2-доменом $\alpha$-цепи рецептора. Это связывание, сопровождаемое реаранжировкой С 23 , вызывает конформационный сдвиг доменов С 2 в сторону рецептора. Показано участие аминокислотных остатков домена С 2 в связывании с рецептором. Создается впечатление, что этот сдвиг повышает аффинность связывания и лишь полноценный Fc-фрагмент IgE способствует конечной медленной скорости диссоциации комплекса $\mathrm{IgE}-\mathrm{Fc}_{\varepsilon} \mathrm{RI}$ (процесс фиксации $\mathrm{IgE}$ на $\mathrm{Fc}_{\varepsilon} \mathrm{RI}$ показан на рис. 2).

Молекула $\operatorname{IgE~по-прежнему~остается~ключевой~}$ в организации аллергического ответа, но ее функции в настоящее время представляются более разнообразными, чем прежде. Перечень типов клеток, на которых может фиксироваться IgE, существенно расширился, а следовательно, и перечень клеток, активируемых IgЕ-зависимым механизмом. Причем следует иметь в виду, что разные типы клеток несут разные типы рецепторов для IgE. Прежде были известны 2 типа IgE-связывающих рецепторов, которые

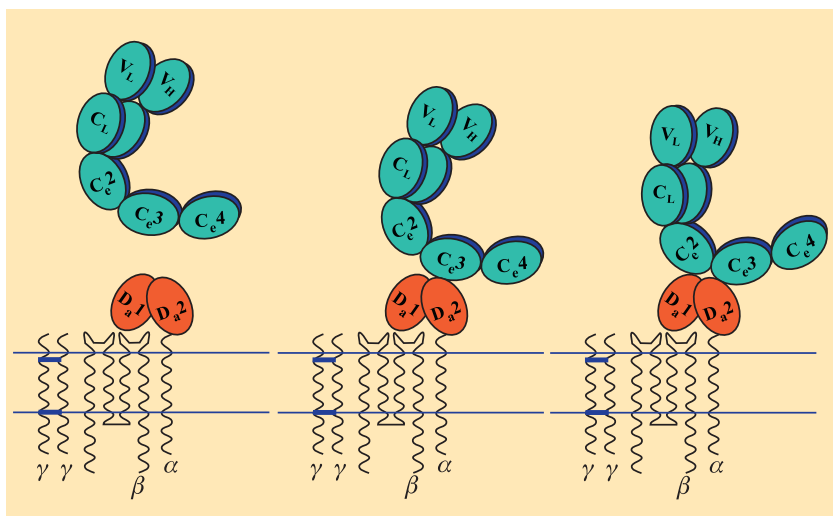

Рис.2. Взаимодействие $\operatorname{IgE~c~Fc} \mathrm{FI}_{\varepsilon}$

Примечание: Молекула IgE, имеющая ригидную асимметричную форму, приближается к встроенному в мембране рецептору $-\mathrm{Fc}_{\varepsilon} \mathrm{RI}$; происходит связывание константных доменов С 33 иммуноглобулина с D2-доменом $\alpha$-цепи $\mathrm{Fc}_{\varepsilon} \mathrm{RI}$; это сопровождается конформационным сдвигом $\mathrm{Fc}_{\varepsilon}$-фрагмента, что делает возможным взаимодействие доменов С 22 иммуноглобулина с D1-доменом $\alpha$-цепи рецептора. Последнее обеспечивает повышенное сродство и высокую прочность связывания IgE c Fc $\mathrm{FI}_{\varepsilon}$ самым подробным образом охарактеризованы к настоящему времени: упомянутый выше высокоаффинный $\mathrm{Fc}_{\varepsilon} \mathrm{RI}$ и низкоаффинный $\mathrm{Fc}_{\varepsilon} \mathrm{RII}$, или CD23. $\mathrm{Fc}_{\varepsilon} \mathrm{RI}$, состоящий из 4 субъединиц $\left(\alpha \beta \gamma_{2}\right)$, представлен на тучных клетках и базофилах, перекрестное связывание рецептора на которых ведет к секреции из них высокоактивных провоспалительных медиаторов (гистамина, лейкотриенов, цитокинов), вызывающих внешние проявления немедленной аллергии. В форме 3 субъединиц $\left(\alpha \gamma_{2}\right) \mathrm{Fc}_{\varepsilon} \mathrm{RI}$ присутствует на моноцитах / макрофагах, клетках Лангерганса, нейтрофилах. Низкоаффинный рецептор (CD23) представлен на В-клетках, активированных Т-клетках, моноцитах, эозинофилах, тромбоцитах, фолликулярных дендритных клетках и некоторых тимических эпителиальных клетках. При связывании IgE с аллергеном CD23 облегчает представление антигена Т-клеткам, а его растворимые фрагменты участвуют в регуляции продукции IgE по механизму обратной связи.

Помимо этих хорошо изученных рецепторов в настоящее время признается существование 3-го типа рецепторов для IgE - галектина-3, который изначально рассматривался просто как IgE-связывающий белок. Как оказалось, в форме рецептора он присутствует на нейтрофилах и участвует в механизме активации этих клеток. Он также обнаружен на клетках трофобласта в плаценте. Здесь галектин-3 рассматривается как один из участников механизма транспорта материнского IgE в плаценту (но не в кровоток плода, куда он не проникает, т. к. не преодолевает фрагмент плацентарного барьера, состоящий из эндотелия фетальных кровеносных сосудов). Клетки Кащенко-Хофбауэра, находящиеся в строме ворсинок плаценты и представляющие собою фетальные макрофаги, связывают IgE (материнского происхождения). Они имеют рецепторы, обозначаемые как DC-SIGN (Dendritic Cell-Specific Intercellular adhesion molecule-3-Grabbing Non-integrin), или CD209. DC-SIGN является лектином С-типа, который функционирует как патоген-распознающий рецептор, индуцирующий разнообразные иммунологические реакции. DC-SIGN связывается с определенными углеводными структурами, в частности с гликоконъюгатами, содержащими маннозу. Это дало основание предположить, что материнский IgE может связываться с DC-SIGN на клетках Хофбауэра за счет содержащих маннозу углеводных остатков, присутствующих в молекуле IgE [23]. Не исключено, что при установлении функции этих ранее не известных рецепторов удастся расширить представления о формах участия IgЕ-опосредованных механизмов в аллергии.

\section{Изменение дозово-временного режима действия аллергена - фактор переключения иммунного ответа}

Обновленное представление о сущности аллергии как вынужденной формы реагирования в ответ на преодоление естественных барьеров аллергенами (в определенном дозово-временном режиме) обосновывает, 
по крайней мере, 2 наиболее перспективных пути противоаллергических вмешательств. Первый из них заключается в создании способов замещения (кстати, эмпирически сравнительно давно используемых) и восстановления нарушенной барьерной функции (эта область пока исследована мало, но потенциально ее изучение наиболее оправдано). Второй путь предусматривает воздействия, обеспечивающие переключение организма с аллергического типа реагирования на иной способ обеспечения противоаллергенного ответа. Все остальное имеет хотя и важное, но вспомогательное значение в устранении неизбежности аллергического ответа на поступление в организм аллергена.

Сегодня, наряду с мерами по исключению аллергенного воздействия, аллерген-специфическая иммунотерапия (АСИТ) является единственным приемом противоаллергического лечения, отвечающим такому требованию и способным изменять характер реагирования иммунной системы на аллерген и влиять тем самым на естественное течение болезни [24, 25].

Непосредственным итогом изменения характера реагирования на аллерген после успешно выполненной АСИТ являются следующие результаты [26]:

- снижение тканевой (органной) чувствительности при воздействии на организм аллергена, что подтверждается как данными клинических наблюдений за больным в период естественной аллергенной экспозиции, так и проведением провокационных проб с аллергеном;

- снижение неспецифической тканевой гиперреактивности, которое проявляется, в частности, снижением чувствительности к разным медиаторам аллергии;

- угнетение признаков аллергического воспаления как морфологических, так и функциональных.

Эти результаты определяют, в свою очередь, клинические последствия АСИТ, наиболее важными из которых являются следующие:

- сохранение длительной ремиссии заболевания после завершения успешных курсов АСИТ;

- предупреждение расширения спектра аллергенов, к которым формируется повышенная чувствительность;

- предупреждение утяжеления течения заболевания и перехода более легких клинических проявлений аллергии в более тяжелые (например, аллергического ринита - в БА);

- уменьшение потребности в противоаллергических лекарственных препаратах.

Механизм достижения лечебного результата АСИТ нельзя объяснить каким-либо одним предпочтительным эффектом. Сейчас уже общепризнанно, что он включает в себя полифункциональное действие на разные звенья аллергического процесса и обеспечивает тем самым коренную перестройку формы реагирования на аллерген. Важно, что это происходит в том же самом организме, ответ которого на аллерген был IgE-опосредованным. Рассмотрение основных точек приложения действия АСИТ иллюстрирует сказанное [24, 25].

\section{Действие АСИТ на продукцию антител разных изотипов}

Во многих работах показано, что АСИТ пыльцевыми аллергенами не приводит или приводит к незначительным изменениям концентрации IgE в сыворотке крови. Вместе с тем сезонный прирост содержания $\mathrm{IgE}$ заметно подавляется после продолжительного лечения. Повторные курсы АСИТ сопровождаются некоторым снижением содержания аллерген-специфического IgE по сравнению с исходным уровнем, но оно не столь выражено, чтобы им можно было объяснить лечебное действие АСИТ.

АСИТ аэроаллергенами уже в течение 1-го года терапии обычно сопровождается повышением содержания в сыворотке крови аллерген-специфических IgG и IgG4. Заметное увеличение сывороточной концентрации IgG4 обнаруживается в пределах первых 60 дней после начала проведения АСИТ ядами перепончатокрылых. Давно возникшее толкование этих сведений состоит в том, что антитела этого изотипа имеют блокирующую активность, обеспечивающую конкуренцию с $\operatorname{IgE~за~связывание~с~аллерге-~}$ ном, что должно угнетать IgE-зависимую активацию тучных клеток, базофилов и других клеток (в частности, дендритных), экспрессирующих рецепторы для $\operatorname{IgE~и,~соответственно,~несущих~на~своей~поверх-~}$ ности IgE. Такие представления согласуются с данными о том, что аллерген-специфический $\mathrm{IgG} 4$, образовавшийся в ходе АСИТ, может блокировать вызванное аллергеном IgE-зависимое высвобождение гистамина из базофилов человека. Эти IgG-антитела могут также подавлять аллерген-специфический Т-клеточный ответ in vitro за счет угнетения IgE-опосредованного представления аллергена В-клеткам.

Что касается клинического значения этих изменений, то оно весьма ограниченно. Дело в том, что не существует четкой связи между концентрациями $\mathrm{IgG-антител} \mathrm{и} \mathrm{клиническими} \mathrm{результатами} \mathrm{АСИТ.}$ При индивидуальном наблюдении за клиническим результатом АСИТ и уровнем аллерген-специфического IgG не удается определить четкого соответствия этих показателей друг другу. Такие же сведения получены еще в период определения биологическим методом блокирующей активности сыворотки крови лиц, прошедших курс АСИТ. Вместе с тем данные группового анализа показывают, что в группе пациентов, прошедших АСИТ, уровень блокирующих антител выше, чем среди тех, кто не получал лечения, а в тех группах, в которых достигнут отличный результат лечения, выше, чем в группах больных с плохим лечебным эффектом.

Правда, известны данные, полученные при оценке лечебной эффективности "стремительной" (rush) АСИТ, которые свидетельствуют о том, что клинически определяемое лечебное действие наступает существенно раньше каких-либо заметных изменений концентрации IgG-антител.

Вместе с тем нет оснований отрицать вклад образования аллерген-специфического IgG в лечебное действие АСИТ. В действительности же блокирую- 
щие антитела могут составлять лишь 1 из нескольких звеньев механизма АСИТ. При проведении АСИТ ядом перепончатокрылых как правило возникает повышение концентрации IgG-антител, чему предшествует изменение специфичности этих антител. Аллерген-специфический IgG, полученный от пациентов с аллергическими реакциями на яд пчел, характеризовался спектром тонкой специфичности, отличным от такового аллерген-специфического $\mathrm{IgG}$, полученного от лиц, имеющих устойчивость к яду, приобретенную либо в естественных условиях (при повторных укусах у пчеловодов) либо благодаря успешной АСИТ.

Нельзя оставлять без внимания и возможное участие антител других изотипов иммуноглобулинов. Известны данные о том, что 2-летний курс АСИТ пыльцевым аллергеном сопровождался возрастанием содержания в сыворотке крови аллерген-специфических антител изотипа IgA2. При этом отмечен прирост содержания полимерной (включающей соединительную J-цепь) формы IgA, а в назальном секрете (по результатам определения мРНК) - увеличение концентрации трансформирущего фактора роста- $\beta$ (TGF- $\beta$ ). Причем, была корреляция между содержанием мРНK TGF- $\beta$ и концентрацией сывороточного аллерген-специфического IgA2. Фракции IgA, полученные после проведения АСИТ, запускали секрецию IL-10 моноцитами, но не угнетали IgE-опосредуемое связывание аллергена В-клетками, что наблюдалось при использовании фракций IgG. Таким образом, вполне вероятно, что действие АСИТ может характеризоваться избирательной стимуляцией IgA2-ответа, что коррелирует с возрастанием в ткани экспрессии TGF- $\beta$ и индуцирует экспрессию IL-10 в моноцитах, внося тем самым некоторый вклад в развитие толерантности у пациентов, прошедших АСИТ.

Сублингвальная АСИТ, проведенная пыльцевыми аллергенами в режиме предсезонных курсов в течение 2 лет, характеризуется заметным действием на продукцию иммуноглобулинов, распространяющимся, главным образом, на IgA, а возрастание содержания IgA соотносится с приростом продукции TGF- $\beta$ [27].

Можно считать, что системные изменения содержания иммуноглобулинов при сублингвальной и инъекционной АСИТ оказываются принципиально сходными. Недавно это было подтверждено на примере изучения сублингвальной АСИТ пыльцевыми аллергенами, которая приводила к возрастанию уровня IgG1- и IgG4- антител и повышению способности сыворотки крови тормозить $\mathrm{IgE-зависимое}$ связывание аллергена В-клетками. Одновременно было показано увеличение сезонных пиковых значений IgA1 и IgA2 после сублингвальной АСИТ [28].

\section{Влияние АСИТ на тучные клетки, базофилы, эозинофилы}

В ряде работ, выполненных разными исследовательскими группами, получены данные о заметном действии АСИТ на образование медиаторов воспаления как в ранней, так и в поздней фазах аллергического ответа. Наиболее эффективной она была при амброзийном поллинозе: удалось добиться значительного уменьшения концентрации медиаторов в назальном секрете у лиц, получавших АСИТ. Принципиально сходные данные недавно получены при проведении 4-месячного курса местной интраназальной АСИТ аллергеном Dermatophagoides pteronissinus, приводившей к статистически значимому угнетению симптомов аллергического ринита и торможению секреции гистамина и эозинофильного катионного белка, обнаруживаемых в отделяемом из Hoca [29].

Эти изменения можно объяснить угнетением трансэпителиальной миграции тучных клеток и поступления в слизистую носа эозинофилов. АСИТ аллергеном домашнего клеща у детей сопровождалась уменьшением числа метахроматических клеток (преимущественно тучных клеток) в отпечатках, полученных со слизистой носа. Правда, при АСИТ пыльцевым аллергеном сезонное возрастание числа тучных клеток в эпителии не отличалось от такового в группе лиц, получивших плацебо.

Более определенные данные получены с эозинофилами. Успешно проведенная АСИТ сопровождается уменьшением поступления в слизистую носа эозинофилов, вызванного провокационной пробой с аллергеном. Эти данные получены при поллинозе у больных с повышенной чувствительностью к пыльце амброзии или злаковых трав. Специально следует подчеркнуть, что торможение поздней фазы аллергического ответа, возникающей при проведении интраназальной провокационной пробы, совпадало с уменьшением числа именно эозинофилов, но не нейтрофилов. Сезонный рост количества эозинофилов в слизистой носа у пациентов, которым была проведена 2-годичная АСИТ аллергеном пыльцы трав, оказывался существенно меньшим, чем в группе сравнения, причем отмечалась значимая связь между числом эозинофилов и величиной суммарной оценки симптомов ринита $[25,30]$.

С этими наблюдениями согласуются известные данные о том, что АСИТ, в результате которой достигнут хороший лечебный эффект, сопровождается уменьшением неспецифической тканевой гиперреактивности. У больных БА, вызванной пыльцой березы, проведение АСИТ позволяло добиться угнетения симптомов заболевания и снижения бронхиальной гиперреактивности, а подавление сезонного возрастания гиперреактивности воздухоносных путей совпадало с уменьшением числа эозинофилов и концентрации эозинофильного катионного белка в лаважной бронхоальвеолярной жидкости.

Что касается базофилов, то АСИТ, по-видимому, существенно не угнетает сезонное возрастание числа этих клеток в слизистой носа. Однако нельзя не упомянуть, что у лиц, прошедших АСИТ, в слизистой носа реже встречались базофилы, чем в слизистой носа пациентов из группы сравнения. Поэтому вполне вероятно, что АСИТ тормозит сезонное увеличение 
содержания в слизистой носа не только эозинофилов, но и, в какой-то степени, базофилов.

\section{Влияние АСИТ на Т-лимфоциты}

В настоящее время наиболее популярной стала такая точка зрения: в процессе АСИТ ключевым и определяющим звеном изменений поведения и активности клеток воспаления и антителообразования является изменение аллерген-специфической реактивности Т-клеток.

Изменение ответа Т-клеток на аллерген наблюдается при достижении клинического положительного результата АСИТ и включает уменьшение вызванного аллергеном пролиферативного ответа Т-клеток и образования IL-4 и одновременно увеличение образования IL-10 и TGF- $\beta$. Выяснение конкретного специфического и целенаправленного действия АСИТ на вызванный аллергеном ответ Т-клеток представляет очевидный интерес, т. к. обосновывает дополнительные пути усовершенствования этого метода лечения.

Снижение вызванного аллергеном пролиферативного ответа Т-клеток периферической крови под действием АСИТ можно считать хорошо установленным и неоднократно подтвержденным фактом, продемонстрированным на примере поллиноза и аллергии к ядам перепончатокрылых. Вполне допустимым будет считать, что этот результат анергии Тклеток достигается высокими дозами аллергена, которые при АСИТ многократно превышают дозы, поступающие в организм при естественной экспозиции аллергенов. Эти различия в дозах особенно велики при использовании сублингвальной АСИТ. Действительно, при испытании in vitro показано, что пролиферация Т-клеток периферической крови больного аллергией тормозится в случае использования высоких концентраций аллергена. Возникающая при этом анергия имеет высокую антигенную специфичность, иными словами, она относится к истинной аллерген-специфической анергии. Подтверждением этого являются известные наблюдения, свидетельствующие о том, что у пациентов, получавших АСИТ ядом пчел, возникало снижение отвечаемости Т-клеток на главный аллергенный компонент яда пчел (фосфолипазу $\mathrm{A}_{2}$ ), но не на иные контрольные антигены (столбнячный анатоксин и туберкулин - PPD).

Важным фактором, ответственным за анергию T-клеток, может быть IL-10. Во многих работах показано, что после проведения АСИТ в периферической крови обнаруживаются Т-клетки, которые продуцируют IL-10 в ответ на стимуляцию аллергеном. Впервые это явление описано при проведении АСИТ ядом пчел, а позже показано, что усиление продукции IL-10 совпадает с торможением пролиферативного ответа Т-клеток и продукции ими цитокинов при стимуляции клеток аллергеном из яда пчел. Подобная выраженная аллерген-специфическая реакция, состоящая в продукции IL-10 in vitro, воспроизводится и на клетках пчеловодов, у которых сформировалась естественная толерантность к яду пчел - при поступлении в организм очень высоких количеств аллергена. Аллерген-специфический и цитокиновый ответы восстанавливались при использовании антител к IL-10. Индукция T-клеток, продуцирующих IL-10, описана также и при традиционной АСИТ пыльцевыми аллергенами.

Следующим результатом действия повторных высоких доз антигена на Т-клетки при проведении АСИТ может быть индукция апоптоза. Повышенная чувствительность лимфоцитов к апоптозу при культивировании клеток с аллергеном обнаруживается после проведения АСИТ аллергенами некоторых трав и деревьев. Причем преимущественно апоптоз захватывал Тh2-клетки.

В условиях in vitro показано, что при испытании высоких доз аллергена клещей домашней пыли пролиферативный ответ Т-клеток угнетается, а число апоптотических клеток возрастает с преимущественным вовлечением в апоптоз Т-клеток $\mathrm{CD}^{+} \mathrm{IL}_{-} 4^{+}$. Следует указать, что в этих условиях возрастает число клеток, которым можно приписать регуляторную функцию, - CD4 ${ }^{+}$INF- $\gamma^{+}$и $\mathrm{CD}^{+} \mathrm{INF}^{-} \gamma^{+}$T-клеток. Таким образом, влияние на уровень пролиферации Т-клеток и апоптоз вносят вклад в склонение реакции в сторону преимущественной продукции INF- $\gamma$ Т-клетками, наблюдаемое при действии высоких концентраций аллергена.

Действительно, главной особенностью изменений, происходящих при АСИТ, является перестраивание иммунного ответа в новый тип реакции, характерный для интенсивной антигенной стимуляции, которая легко достигается парентеральным (не через барьерные ткани) поступлением антигена. АСИТ через слизистые оболочки, как, например, сублингвальная иммунотерапия, предусматривает использование очень высоких доз аллергена, намного превышающих порог аллергенной проницаемости барьерных систем. Поэтому и в этом случае речь идет о высокодозовой антигенной стимуляции иммунной системы организма.

Свидетельством перестройки иммунного ответа на новый тип являются давно известные данные о том, что вместе с подавлением пролиферативных ответов Т-лимфоцитов происходит уменьшение образования цитокинов Th2-профиля при аллергенной стимуляции в культуре клеток, полученных после проведения АСИТ. При этом абсолютные значения продукции INF- $\gamma$ T-клетками периферической крови не возрастают, но обычно отмечается уменьшение отношения уровня IL-4 или IL-5 к INF- $\gamma$ и приближение величин этого отношения к показателям практически здоровых лиц. Наиболее вероятным механизмом этих изменений считают переключение пути дифференцировки наивных аллерген-специфических Т-клеток, а не изменение характера продукции цитокинов коммитированными Тh2-клетками.

Однако нельзя упускать из виду, что кратковременные изменения цитокинового профиля, способствующие продукции INF- $\gamma \mathrm{CD}^{+}{ }^{+}$и $\mathrm{CD} 8^{+} \mathrm{T}$-клетками, могут быть воспроизведены в поликлональной 
и моноклональной популяциях Т-клеток при стимуляции высокими концентрациями аллергена. В свою очередь, локальные высокие концентрации INF- $\gamma$ могут способствовать перестройке иммунного ответа за счет торможения вызываемой IL-4 экспрессии транскрипта $\varepsilon$-цепей.

В подкрепление такого представления могут быть использованы сравнительно давно полученные данные о том, что после проведения эффективной АСИТ пыльцевыми аллергенами в слизистой носа обнаруживается повышение экспрессии мРНК для INF- $\gamma$ и IL-12. Известно также, что высокие дозы аллергена в условиях in vitro усиливали экспрессию молекул адгезии (CD62L и CD49d ${ }^{\mathrm{hi}}$ ) и хемокинового рецептора (CCR5) на INF- $\gamma^{+}$T-клетках периферической крови лиц с повышенной чувствительностью к аллергену клеща домашней пыли. Поэтому можно предположить, что увеличение в ткани числа INF- $\gamma^{+}$ Т-клеток после АСИТ обусловлено повышением направленного движения этих клеток в периферические ткани, подвергаемые действию аллергена.

В целом ряде работ показано, что после проведения АСИТ в периферической крови пациентов обнаруживаются Т-клетки, которые образуют IL-10 в ответ на стимуляцию in vitro аллергеном. Впервые это явление описано на примере АСИТ ядом пчел. Позже обнаружили, что такое усиление продукции IL-10 накладывается на выраженное подавление образования Т-клеточных цитокинов и пролиферативного ответа, вызванных в условиях in vitro ядом пчел. Такой же характер реагирования на аллерген получен и у пчеловодов, у которых в естественных условиях развилась толерантность к яду при повторных многократных укусах. Восстановление цитокинового и пролиферативного ответов, вызванных in vitro аллергеном, происходило при использовании антител, нейтрализующих IL-10. Эти наблюдения дали серьезный повод считать, что достигаемая иммунотерапией усиленная продукция IL-10 имеет решающее значение в подавлении Т-клеточного ответа и развитии аллерген-специфической анергии, а во взаимодействии с соответствующим цитокиновым микроокружением может оказывать также сопутствующее действие на переключение с Th2- на Th1цитокиновый тип ответа. В настоящее время индукция Т-клеток, продуцирующих IL-10, показана и при традиционной АСИТ пыльцевыми аллергенами. IL-10 имеет широкий спектр противоаллергических свойств, включающих перевод индуцированного интерлейкином-4 образования IgE В-клетками на антитела другого изотипа (IgG1, IgG4 и IgA), торможение IgE-зависимой активации тучных клеток, угнетение образования цитокинов эозинофилами и их выживания, в Т-клетках (наряду с развитием упомянутой выше анергии) подавление образования таких проаллергических цитокинов, как IL-5. Легко допустить, что все эти эффекты, опосредуемые IL-10, могут включаться в клинически проявляющееся лечебное действие АСИТ. Справедливости ради надо заметить, что IL-10 экспрессируется разными клетками иммунной системы человека, включая
Тh-клетки, В-клетки, моноциты / макрофаги, дендритные клетки, тучные клетки, эозинофилы. Поэтому участие этого медиатора в механизме АСИТ является, по-видимому, значительно более широким, чем это представляется в настоящее время.

Подробный анализ Т-клеточных ответов в ходе АСИТ привел к формированию представлений о том, что регуляторные Т-клетки выполняют направляющую роль в сдерживании и торможении Th2-поляризации иммунного ответа на аллерген и в переключении его на другой тип.

При наблюдении за больными, проходящими АСИТ аллергенами пыльцы растений и ядом пчел, показано заметное возрастание активности регуляторных Т-клеток (Treg), которая оказывается сниженной у больных с атопическими проявлениями. Особо следует обратить внимание на прогрессивное возрастание доли $\mathrm{CD} 4^{+} \mathrm{CD} 25^{+h i g h}$ Т-клеток и T-клеток, продуцирующих IL-10, параллельно переключению с Th2- на Th1-профиль в течение проводимой АСИТ ядом пчел [31]. Активация Treg становилась заметной уже вскоре после 1-й лечебной инъекции (через 6 ч). О значении активации регуляторных клеток в осуществлении лечебного действия АСИТ свидетельствуют результаты сопоставления активности Treg и клинической переносимости АСИТ. С одной стороны, возрастание активности Treg наступало раньше у тех пациентов, у которых не было тяжелых реакций на лечебное введение яда, и это возрастание было связано с отчетливым увеличением числа клеток IL-10 $0^{+}$и INF- $\gamma^{+}$. C другой стороны, возникновение в ходе лечения нежелательных побочных эффектов в виде анафилактических реакций, было прямо связано с отсутствием индукции Treg и IL $10^{+}$и переключения с Th2-ответа на Th1-ответ.

При пыльцевой аллергии показано, что после проведения 2-летней АСИТ повышается число IL-10+ ${ }^{+}$клеток (по мРНК и белку), инфильтрирующих слизистую носа, но это увеличение обнаруживается только в период экспозиции аллергена (в сезон палинации). Такие изменения не возникали у пациентов, получавших плацебо, или у практически здоровых лиц. После проведения АСИТ Т-клетки периферической крови, культивируемые в присутствии пыльцевого аллергена, как и тканевые клетки, обнаруживали способность продуцировать IL-10. Одновременно показано, что АСИТ приводила к устранению сезонного прироста содержания в сыворотке крови аллерген-специфического IgE, к 60-80-кратному увеличению концентрации аллерген-специфического IgG и 100-кратному - количества содержания аллерген-специфического IgG4. В целом в группе пациентов увеличение содержания IgG и опосредуемой $\mathrm{IgG}$ "блокирующей" активности совпадало с положительным лечебным результатом АСИТ [32].

Наконец, после 2-летней АСИТ в слизистой носа повысилось содержание Foxp $3^{+} \mathrm{CD} 4^{+} \mathrm{CD} 25^{+} \mathrm{T}$-клеток в сезон палинации по сравнению с периодом до лечения. Вне сезона палинации у пациентов, прошедших АСИТ, содержание этих Treg в слизистой 
носа было значительно выше, чем у больных, не получавших АСИТ [33].

Клинические исследования, на основании которых можно судить об особенностях механизма сублингвальной АСИТ, существенно различаются использованными аллергенами, их дозами, продолжительностью лечения и прочими факторами, поэтому определенное толкование полученных результатов оказывается довольно затруднительным. Тем не менее надо иметь в виду, что непосредственная абсорбция аллергена через слизистую полости рта при его подъязычном нанесении не выражена. Поэтому исследователи склоняются к тому, что клинический результат такой АСИТ обусловлен, прежде всего, взаимодействием аллергена (его высоких доз) с иммунной системой слизистой оболочки. При помощи меченного радионуклидом аллергена показано, что при сублингвальном применении аллерген задерживался в слизистой оболочке не менее чем на 2 ч (по некоторым данным - до 18-20 ч). С этим связывают возможность сильного местного воздействия аллергена на клетки иммунной системы слизистой с последующим общим (системным) действием. Учитывая известные сведения о функции слизистой оболочки полости рта как толерогенного органа, полагают, что продуктивность действия сублингвального применения аллергена может быть объяснена как раз этим свойством. Однако это остается предположением, требующим специальных доказательств.

Полагают, что захват аллергена специализированными антиген-представляющими клетками в пределах слизистой оболочки является первым и необходимым звеном успешной сублингвальной АСИТ. Дендритные клетки, включая клетки Лангерганса, обильно представленные в слизистой оболочке полости рта и несущие на своей поверхности рецепторы для IgE (Fc $\left.\mathrm{FI}_{\varepsilon}\right)$, секретируют IL-10 и индуцируют in vitro клетки с фенотипом регуляторных Т-клеток. Выше упоминалось недавно выполненное комплексное исследование, проведенное на пациентах, получавших сублингвальную АСИТ [28]. Итогом этого исследования явилось установление возрастания числа Foxp3 ${ }^{+}$клеток в слизистой оболочке подъязычной области, что совпадало с системными изменениями, ранее описанными для обычной АСИТ. Кроме того, происходило увеличение содержания в сыворотке крови аллерген-специфических IgG1 и $\mathrm{IgG} 4$, возрастание пикового сезонного прироста уровня IgA1 и IgA2, а также появлялась и повышалась в ходе сублингвальной иммунотерапии блокирующая активность сыворотки крови. Последнюю определяли in vitro по способности тормозить IgEопосредованное связывание аллергена с В-лимфоцитами.

На примере пыльцевого аллергического ринита показано, что курсы предсезонной сублингвальной АСИТ, проведенной в течение 2 лет, приводят наряду с возрастанием уровня аллергенспецифического $\operatorname{IgE~к~повышению~концентрации~в~сыворотке~крови~}$ аллерген-спеифических IgG, IgG4, IgA, а также

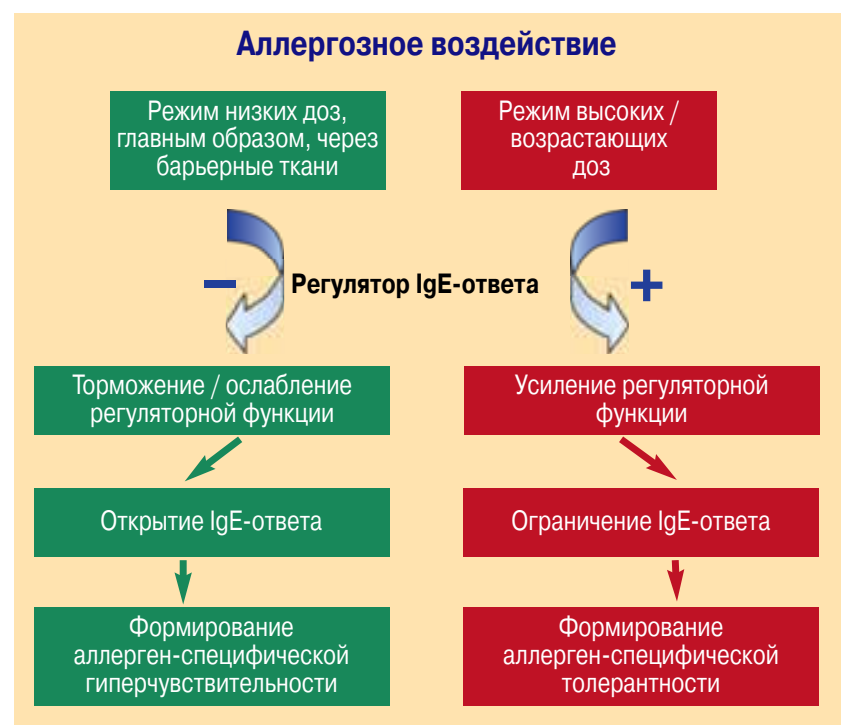

Рис. 3. Зависимость формирования аллерген-специфической гиперчувствительности или толерантности от силы аллергенного воздействия

TGF- $\beta$. При этом была установлена достоверная связь между приростом IgA и TGF- $\beta$, как после 1-го, так и 2-го курса сублингвальной АСИТ [27], что свидетельствует об индукции тех же регуляторных факторов и видоизменении иммунного ответа, что и при обычной АСИТ.

Таким образом, наиболее заметным последствием разных вариантов АСИТ, предусматривающей высокодозовую антигенную стимуляцию, оказываются такие изменения регуляторной функции, которые переключают иммунный ответ на другой тип, ведущий к торможению аллергической гиперчувствительности и замене ее состоянием аллерген-специфической толерантности (рис. 3). Еще раз необходимо подчеркнуть важное обстоятельство, состоящее в том, что перестройка реагирования иммунной системы оказывается осуществимой в том же самом организме, в котором ранее сформировался аллергический тип реактивности по отношению к тому же самому аллергену, но преподнесенному организму в ином временном и дозовом режиме. Это обстоятельство является решающим аргументом в пользу того, что аллергия не может однозначно рассматриваться как изначальный "дефект" или "поломка" иммунной системы, а представляет собою специализированную форму реагирования на низкие дозы аллергенов, поступающих в естественных условиях через барьерные ткани. Такое проникновение может быть обусловлено либо повышением барьерной проницаемости для аллергена, либо превышением аллергеном порога проницаемости. Следовательно, создание новых перспективных противоаллергических мер должно быть направлено, во-первых, на восстановление нарушенной противоаллергенной функции тканевых барьеров, а с другой - на коррекцию окружающей аллергенной среды. На сегодня АСИТ остается единственным патогенетически наиболее оправданным методом лечения аллергических состояний, обеспечивающим переключение иммунного ответа на новый тип, влияющий на все звенья 
патогенеза аллергии, изменяющий тем самым клиническое течение заболевания и устраняющий необходимость поддержания аллергического ответа.

\section{Литература}

1. Asher M.I., Montefort S., Bjorksten B. et al. Wordwide time trends in the prevalence of symptoms of asthma, allergic rhinoconjunctivitis, and eczema in childhood: ISAAC phases one and three repeat multicountry cross-sectional surveys. Lancet 2006; 368: 733-743.

2. Floistrup H., Swartz J., Bergstrom A. et al. Allergic disease and sensitization in Steiner school children. J. Allergy Clin. Immunol. 2006; 117: 59-66.

3. van Schayck C.P., Smit H.A. The prevalence of asthma in children: a reversing trend. Eur. Respir. J. 2005; 26: 647-650.

4. Ponsonby A.L., Glasgow N., Pezic A. et al. A temporal decline in asthma but not eczema prevalence from 2000 to 2005 at school entry in the Australian Capital Territory with further consideration of country of birth. Int. J. Epidemiol. 2008; 37: 559-569.

5. Anandan C., Nurmatov U., van Schayck O.C.P., Sheikh A. Is the prevalence of asthma declining? Systematic review of epidemiological studies. Allergy 2010; 65: 152-167.

6. Gell P.G.H., Coombs R.P.A. Clinical aspects of immunology. Philadelphia: F.A.Davis Co.; 1964.

7. Blaser $K$. Role of T-cell subtypes in allergic inflammation. Chem. Immunol. Allergy 2008; 94: XI-XV.

8. Miller R.L. Prenatal maternal diet affects asthma risk in offspring. J. Clin. Invest. 2008; 118: 3265-3268.

9. Miller R.L., Ho S.M. Environmental epigenetics and asthma: current concepts and call for studies. Am. J. Respir. Crit. Care Med. 2008; 177: 567-573.

10. Martino D.J., Prescott S.L. Silent mysteries: epigenetic paradigms could hold the key to conquering the epidemic of allergy and immune disease. Allergy 2010; 65: 7-15.

11. Гущин И.С. Немедленная аллергия клетки. М.: Медицина; 1976.

12. Гущин И.С. Об элементах биологической целесообразности аллергической реактивности. Пат. физиол. 1979; 4: 3-11.

13. Гущин И.С. Преодоление аллергеном тканевого барьера - решающая форма предрасположения к аллергии. Пат. физиол. 2009; 1: 8-13.

14. Ярилин A.A. TSLP (лимфопоэтин из стромы тимуса) новый патогенетический фактор аллергии. Рос. аллергол. журн. 2008; 5: 9-13.

15. Rochman $Y$., Leonard $W$. Thymic stromal lymphopoietin: a new cytokine in asthma. Curr. Opin. Pharmacol. 2008; 8: 249-253.

16. Wang Y.H., Liu Y.J. Thymic stromal lymphopoietin, OX40ligand and interleukin-25 in allergic responses. Clin. Exp. Allergy 2009; 39: 798-806.

17. Liu Y. TSLP in epithelium cell and dendritic cell cross talk. Adv. Immunol. 2009; 101: 1-25.

18. Wang Y.H., Liu Y.J. OX40-OX40L interactions: a promising therapeutic target for allergic diseases? J. Clin. Invest. 2007; 117: 3655-3657.

19. Zhang Z., Hener P., Frossard N. et al. Thymic stromal lymphopoietin overproduced by keratinocytes in mouse skin aggravates experimental asthma. Proc. Natl. Acad. Sci. USA 2009; 106: 1536-1541.

20. Gould H.J., Sutton B.J., Beavil A.J. et al. The biology of IgE and the basis of allergic disease. Annu. Rev. Immunol. 2003; 21: 579-628.

21. Vangelista L. Curent progress in understanding of IgEFce RI interaction. Int. Arch. Allergy Immunol. 2003; 131: 222-233.

22. Гущин И.С. Взаимодействие IgE c Fce RI как объект антиаллергического воздействия. Рос. аллергол. журн. 2005; 1: 7-18.

23. Rindsjo E., Joerink M., Papadogiannakis N., Scheynius A. IgE in the human placenta: why there? Allergy. 2010; 65: 554-560.

24. Forth Edition. Lockey R.F., Ledfprd D.K., eds. Allergens and allergen immunotherapy. New York: Marcel Dekker, Inc; 2008.

25. Rolland J.M., Gardner L.M., O'Hehir R.E. Allergen-related approaches to immunotherapy. Pharmacol. Ther. 2009; 121: 273-284.

26. Гущин И.С., Курбачева О.М. Аллерген-специфическая иммунотерапия атопических заболеваний. (Пособие для врачей). М.; 2002.

27. Ciprandi G., De Amici M., Tosca M.A. et al. Sublingual immunotherapy affects specific antibody and TGF-beta serum levels in patients with allergic rhinitis. Int. J. Immunopathol. 2009; 22: 1089-1096.

28. Scadding G.W., Shamji M.H., Jacobson M.R. et al. Sublingual grass pollen immunotherapy is associated with increases in sublingual Foxp3-expressory cells and elevated allergen-specific immunoglobulin G4, immunoglobulin A and serum inhibitory activity for immunoglobulin E-facilitated allergen binding to B-cells. Clin. Exp. Allergy 2010; 40: 598-606.

29. Tsai J.J., Liao E.C., Tsai F.H. et al. The affect of local nasal immunotherapy in allergic rhinitis: using strips of the allergen dermatophagoides pteronossinus. J. Asthma 2009; 46: 165-170.

30. Till S.J., Durham S.R. Immunological responces to allergen immunotherapy. In: Lockley R.F., Bukantz S.C., Bousquet J. Allergen and allergen immunotherapy. $3^{\text {rd }}$ Ed. Revised and expanded. New York: Marcell Dekker, Inc.; 2004. 85-98.

31. Pipet A., Botturi K., Pinot D. et al. Allergen-specific immunotherapy in allergic rhinitis and asthma. Mechanisms and proof of efficacy. Respir. Med. 2009; 103: 800-812.

32. Nouri-Aria K.T., Wachholz P.A., Francis J.N. et al. Grass pollen immunotherapy induces mucosal and peripheral IL10 responses and blocking IgG activity. J. Immunol. 2004; 172: 3252-3259.

33. Radulovic S., Jacobson M.R., Durham S.R., Nouri-Aria K.T. Grass pollen immunotherapy induces Foxp3-expressing $\mathrm{CD}^{+} \mathrm{CD}^{+} 5^{+}$cells in the nasal mucosa. J. Allergy Clin. Immunol. 2008; 121: 1467-1472.

\section{Информация об авторе}

Гущин Игорь Сергеевич - член-корр. РАМН, д. м. н., проф., зав. отделом аллергологии и клинической иммунологии Института иммунологии ФМБА России; тел.: (499) 612-99-54; e-mail: igushchin@yandex.ru

Поступила 15.06.10 () Гущин И.С., 2010 удк 616-056.3-08 